\title{
CORRECTION
}

\section{Correction to: Wearable Ag-NyW textile electrode for continuous ECG monitoring}

\author{
Srinivasulu Avvaru ${ }^{1,2} \cdot$ N. Sriraam ${ }^{3} \cdot$ V. S. Prakash ${ }^{4} \cdot$ Sarthak Sahoo $^{4}$
}

Published online: 11 May 2021

○) Sociedade Brasileira de Engenharia Biomedica 2021

\section{Correction to: Res. Biomed. Eng}

https://doi.org/10.1007/s42600-021-00147-2

When we published the article on 26 April 2021, there was a typographical error in the name of the third author that sadly remained unnoticed during the production process. Instead of "Praksh" his family name is correctly spelled "Prakash".

The publisher apologises for this mistake.

Publisher's Note Springer Nature remains neutral with regard to jurisdictional claims in published maps and institutional affiliations.

The original article can be found online at https://doi.org/10.1007/ s40804-021-00212-4.

N. Sriraam

sriraam@msrit.edu

Srinivasulu Avvaru

sreesri.avvaru@gmail.com

1 Research Scholar, Center for Medical Electronics and Computing, M.S Ramaiah Institute of Technology, Bangalore, Affiliated to VTU, Belgaum, India

2 Department of Electrical, Electronics and Communication Engineering, GITAM, Bangalore Campus, Bangalore, India

3 Center for Medical Electronics and Computing, M.S Ramaiah Institute of Technology, Bangalore, India

4 Department of Cardiology, M.S. Ramaiah Medical College and Hospitals, Bangalore, India 